\title{
Comparison of intraoperative cortisol levels after preoperative hydrocortisone administration versus placebo in patients without adrenal insufficiency undergoing endoscopic transsphenoidal removal of nonfunctioning pituitary adenomas: a double-blind randomized trial
}

\author{
Hyung-Chul Lee, MD, PhD, ${ }^{1}$ Hyun-Kyu Yoon, MD, ${ }^{1}$ Jung Hee Kim, MD, PhD, ${ }^{2}$ \\ Yong Hwy Kim, MD, PhD, ${ }^{3}$ and Hee-Pyoung Park, MD, PhD' \\ Departments of ${ }^{1}$ Anesthesiology and Pain Medicine, ${ }^{2}$ Medicine, and ${ }^{3}$ Neurosurgery, Seoul National University College of \\ Medicine, Seoul National University Hospital, Seoul, Korea
}

\begin{abstract}
OBJECTIVE In this double-blind randomized trial, the necessity of preoperative steroid administration in patients without adrenal insufficiency (AI) undergoing endoscopic transsphenoidal surgery (ETSS) for pituitary adenoma was evaluated.

METHODS Forty patients with and without Al, defined as a peak cortisol level $>18 \mu \mathrm{g} / \mathrm{dl}$ on the insulin tolerance test or rapid adrenocorticotropic hormone (ACTH) test, undergoing ETSS for nonfunctioning pituitary adenomas were randomly allocated to treatment with either $100 \mathrm{mg}$ of preoperative hydrocortisone (group HC, $n=20$ ) or normal saline (group $\mathrm{C}, \mathrm{n}$ $=20$ ). The patients with pituitary apoplexy, the use of a drug within the last 3 months that could affect the hypothalamicpituitary-adrenal axis, or a previous history of brain or adrenal surgery were excluded. Intraoperative cortisol and ACTH levels were measured after anesthesia induction, dura incision, and tumor removal, and at the end of surgery. Intraoperative hypotension, early postoperative $\mathrm{Al}$, and postoperative 3-month pituitary function were investigated.
\end{abstract}

RESULTS Intraoperative serum cortisol levels were significantly higher in the $\mathrm{HC}$ group than in the $\mathrm{C}$ group after anesthesia induction (median $69.0 \mu \mathrm{g} / \mathrm{dl}$ [IQR 62.2-89.6 $\mu \mathrm{g} / \mathrm{dl}]$ vs $12.7 \mu \mathrm{g} / \mathrm{dl}$ [IQR 8.4-18.2 $\mu \mathrm{g} / \mathrm{dl}]$, median difference $57.5 \mu \mathrm{g} /$ dl [95\% Cl 33.0-172.9 $\mu \mathrm{g} / \mathrm{dl}]$ ]), after dura incision (median $53.2 \mu \mathrm{g} / \mathrm{dl}$ [IQR 44.9-63.8 $\mu \mathrm{g} / \mathrm{dl}]$ vs 6.4 [IQR 4.8-9.2 $\mu \mathrm{g} / \mathrm{dl}]$, median difference $46.6 \mu \mathrm{g} / \mathrm{dl}[$ [95\% Cl 13.3-89.2 $\mu \mathrm{g} / \mathrm{dl}]$ ), after tumor removal (median $49.5 \mu \mathrm{g} / \mathrm{dl}$ [IQR 43.6-62.4 $\mu \mathrm{g} / \mathrm{dl}]$ vs $9.2 \mu \mathrm{g} / \mathrm{dl}$ [IQR $5.75-16.7 \mu \mathrm{g} / \mathrm{dl}]$, median difference $39.4 \mu \mathrm{g} / \mathrm{dl}[95 \% \mathrm{Cl} 0.3-78.1 \mu \mathrm{g} / \mathrm{dl}]$ ), and at the end of surgery (median $46.9 \mu \mathrm{g} / \mathrm{dl}$ [IQR $40.1-63.4 \mu \mathrm{g} / \mathrm{dl}]$ vs $16.9 \mu \mathrm{g} / \mathrm{dl}$ [IQR $12.1-23.2 \mu \mathrm{g} / \mathrm{dl}]$, median difference $32.2 \mu \mathrm{g} / \mathrm{dl}[95 \% \mathrm{Cl}-42.0$ to $228.1 \mu \mathrm{g} / \mathrm{dl}]$ ). Serum ACTH levels were significantly lower in group HC than in group $\mathrm{C}$ after anesthesia induction (median $3.9 \mathrm{pmol} / \mathrm{L}$ [IQR $1.7-5.2 \mathrm{pmol} / \mathrm{L}]$ vs $6.9 \mathrm{pmol} / \mathrm{L}$ [IQR $3.9-11.9 \mathrm{pmol} / \mathrm{L}], \mathrm{p}=0.007)$. No patient showed intraoperative hypotension due to Al. Early postoperative Al was observed in 3 and 5 patients in groups $\mathrm{HC}$ and $\mathrm{C}$, respectively. The postoperative 3-month pituitary hormone outcomes including ACTH deficiency were not different between groups.

CONCLUSIONS Preoperative steroid administration may be unnecessary in patients without Al undergoing ETSS for nonfunctioning pituitary adenomas. However, a further large-scale study is needed to determine whether preoperative steroid administration has a significant impact on clinically meaningful events such as perioperative $\mathrm{Al}$ and postoperative 3-month ACTH deficiency in these patients.

Korean Clinical Trial Registry no.: KCT0002426 (https://cris.nih.go.kr/cris/).

https://thejns.org/doi/abs/10.3171/2019.11.JNS192381

KEYWORDS hydrocortisone; pituitary-adrenal system; preoperative care; nonfunctioning pituitary adenoma; transsphenoidal surgery; pituitary surgery

\footnotetext{
ABBREVIATIONS $\mathrm{ACTH}=$ adrenocorticotropic hormone; $\mathrm{Al}=$ adrenal insufficiency; $\mathrm{ETSS}=$ endoscopic transsphenoidal surgery; $\mathrm{GH}=$ growth hormone; $\mathrm{GN}=$ gonadotropin; HPA = hypothalamic-pituitary-adrenal; HR = heart rate; ICU = intensive care unit; NFPA = nonfunctioning pituitary adenoma; PONV = postoperative nausea and vomiting; $\mathrm{SBP}=$ systolic blood pressure; $\mathrm{TSH}=$ thyroid-stimulating hormone.
}

SUBMITTED August 31, 2019. ACCEPTED November 15, 2019.

INCLUDE WHEN CITING Published online January 24, 2020; DOI: 10.3171/2019.11.JNS192381. 
$\mathrm{S}$ URGICAL stimuli provoke the neuroendocrine stress response by activating both the hypothalamic-pituitary-adrenal (HPA) axis and sympathetic nervous system, resulting in significantly increased serum adrenocorticotropic hormone (ACTH), cortisol, and catecholamine levels. ${ }^{11,20,21}$ Specifically, in patients undergoing endoscopic transsphenoidal surgery (ETSS) for pituitary adenoma, the neuroendocrine stress response can be complicated by various factors: 1 ) the pituitary tumor can affect the HPA axis function directly by secreting pituitary hormones and indirectly by suppressing the gland and stalk due to the mass effect; 2) direct surgical manipulation of the pituitary gland as well as intraoperative relocation of the gland due to decompression of the mass; 3) steroids administered preoperatively may affect the stress response via negative feedback mechanisms.

Regarding perioperative steroid administration in patients undergoing ETSS for nonfunctioning pituitary adenoma (NFPA), preoperative steroid replacement for patients with a compromised HPA axis can be necessary to prevent potential problems associated with acute adrenal insufficiency (AI) due to an impaired cortisol stress response to surgical stimuli. ${ }^{22,29}$ However, whether preoperative steroid administration is necessary for patients with an intact HPA axis remains controversial. ${ }^{6,13,25-27,31}$ Although numerous previous studies did not suggest preoperative steroid administration for patients with an intact HPA axis, their suggestion was based on evidence obtained from mostly retrospective and a few prospective observational studies, in which serum cortisol levels were measured in the immediate or early postoperative period. $3,6,13,26,27,30,31$ To date, no study has been conducted to investigate an association between intraoperative clinical signs (i.e., hypotension) due to AI and serum cortisol levels in patients undergoing ETSS. As a result, preoperative steroid administration is still used in some hospitals in clinical practice due to concerns regarding intraoperative hemodynamic instability and postoperative AI. However, this practice in patients undergoing ETSS renders postoperative interpretation of the HPA axis function difficult. In addition, preoperative steroid replacement therapy is associated with various adverse effects, such as increased osteopenia, delayed vasopressin release in response to increased plasma osmolality, and increased postoperative mortality. ${ }^{23,24,28,32}$

In this study we investigated whether preoperative steroid administration is necessary for patients without AI undergoing ETSS for NFPA resection. Intraoperative cortisol levels (the primary outcome measure), intraoperative ACTH and glucose levels, and the incidences of intraoperative hypotension, early postoperative AI, postoperative complications, and postoperative 3-month pituitary hormone deficiency were compared between patients with and without preoperative steroids without AI. We hypothesized that preoperative steroids in patients without AI undergoing ETSS for NFPA would cause a significant, but unnecessary, increase in intraoperative cortisol concentrations.

\section{Methods}

\section{Study Population}

The present study was approved by the IRB of Seoul
National University Hospital and registered at the National Clinical Trial Registry (clinical trial no. KCT0002426; https://cris.nih.go.kr/cris/). Written informed consent was obtained from all study participants. Patients 20-80 years old with an NFPA scheduled for ETSS at 8 AM in Seoul National University Hospital from September 2017 to October 2018 were enrolled in the present study. Among them, patients without preoperative AI, which was defined as a peak cortisol level $>18 \mu \mathrm{g} / \mathrm{dl}$ on the insulin tolerance test or rapid ACTH test, were included. The exclusion criteria were pituitary apoplexy, the use of a drug within the last 3 months that could affect the HPA axis (such as oral pills, etomidate, ketoconazole, metyrapone, mitotane, tyrosine kinase inhibitors, megestrol, and anticoagulants), or a previous history of brain or adrenal surgery.

Patients were randomly assigned to the steroid group ( $\mathrm{HC}$ group) or the placebo group (C group) using a computer-generated 1-to-1 random allocation table with a block size of 4 and 6 generated by a research assistant who did not otherwise participate in the study. The allocation order was concealed in an opaque envelope and was disclosed 1 hour before anesthesia induction by a neurosurgical nurse who did not participate in the overall care of patients. Thirty minutes before anesthesia induction, 100 $\mathrm{mg}$ of hydrocortisone mixed with $100 \mathrm{ml}$ of normal saline was administered intravenously in group HC, and $100 \mathrm{ml}$ of normal saline was administered to patients in group C. In both groups, the saline bag did not have any label showing drug information and only had the "study drug" label. All treatments, except preoperative steroid administration, were the same in both groups. All neurosurgeons, anesthesiologists, intensivists, and patients were blinded to the groups.

\section{Intraoperative and Postoperative Management}

Patients were admitted to the operating room without any premedication except for the study drug, and standard monitors (electrocardiogram, noninvasive blood pressure, peripheral oxygen saturation) were attached. Anesthesia was induced and maintained using the target-controlled infusion of propofol and remifentanil. To facilitate tracheal intubation, rocuronium $(0.6 \mathrm{mg} / \mathrm{kg})$ was administered. A 20-gauge catheter was inserted into the radial artery for continuous blood pressure monitoring. If unexplainable intraoperative hypotension refractory to vasopressor or fluid administration persisted for 10 minutes, serum cortisol and ACTH concentrations were evaluated for biochemical confirmation of AI, and $100 \mathrm{mg}$ of hydrocortisone was intravenously administered regardless of the test results. Patients who transiently received steroids for the treatment of cerebral edema, airway edema, severe nausea, or vomiting during and immediately after the surgery were recorded and excluded from the statistical analysis. Ramosetron $(0.3 \mathrm{mg})$ and fentanyl $(1 \mu \mathrm{g} / \mathrm{kg})$ were given to all patients 5 minutes before the end of surgery to prevent postoperative nausea and vomiting (PONV) and reduce postoperative pain, respectively. After surgery, patients were transferred to the intensive care unit (ICU) without emergence after we examined an immediate postoperative brain CT scan. 


\section{Data Collection}

Serum cortisol, ACTH, and glucose concentrations were measured intraoperatively at four time points: after anesthesia induction, after dura incision, after tumor removal, and at the end of surgery. In addition, serum morning cortisol levels were measured on postoperative days 1-3. Serum cortisol and ACTH concentrations were measured by radioimmunoassay and immunoradiometric assay, respectively. The incidence and duration of hypotension (systolic blood pressure [SBP] $<80 \mathrm{~mm} \mathrm{Hg}$ ), tachycardia (heart rate $[\mathrm{HR}]>120 \mathrm{bpm}$ ), and bradycardia (HR $<40 \mathrm{bpm}$ ) were recorded during surgery and the ICU stay. In addition, hyponatremia and PONV were recorded. The presence of postoperative complications including CNS infection, CSF leakage, hemorrhage, hydrocephalus, delayed hyponatremia, and diabetes insipidus was also recorded.

In all patients, a follow-up pituitary function test was performed to evaluate the neuroendocrine functional outcome at 3 months after surgery. Specifically, the insulin tolerance test or rapid ACTH stimulation test was performed to evaluate ACTH deficiency.

In this study, the primary outcome measure was intraoperative serum cortisol levels. Secondary outcome measures were intraoperative ACTH and glucose levels and the incidences of intraoperative hypotension, early postoperative AI, postoperative complications, and postoperative 3-month pituitary hormone deficiency.

\section{Definition of Pituitary Hormone Deficiency}

Early AI was defined as a serum morning cortisol concentration $<5 \mu \mathrm{g} / \mathrm{dl}$ on postoperative days $1-3 .{ }^{14} \mathrm{ACTH}$ deficiency was defined as serum cortisol $<18 \mu \mathrm{g} / \mathrm{dl}$ in the insulin tolerance test or rapid ACTH stimulation test. Thyroid-stimulating hormone (TSH) deficiency was defined as serum free thyroxine level $<0.7 \mathrm{ng} / \mathrm{dl}$ with a low to normal TSH level. Growth hormone (GH) deficiency was defined as peak $\mathrm{GH}<3 \mathrm{ng} / \mathrm{ml}$ in the insulin-induced stimulation test or as insulin-like growth factor- $1<76 \mathrm{ng} / \mathrm{ml}$, combined with concurrent deficiencies of ACTH, TSH, and gonadotropin (GN). GN deficiency was defined as testosterone < $2.7 \mathrm{ng} / \mathrm{ml}$ in men. For women, GN deficiency was defined as the presence of menstrual disorders in premenopausal patients and as follicle-stimulating hormone $<30 \mathrm{mIU} / \mathrm{ml}$ and estradiol $>50 \mathrm{pg} / \mathrm{ml}$ in postmenopausal patients.

\section{Sample Size Calculation}

In a retrospective review of 18 patients without preoperative AI who received ETSS at 8 AM for NFPA at our institution, the mean cortisol level ( \pm standard deviation) measured immediately after surgery was $52.0 \pm 16.2 \mu \mathrm{g} /$ dl. In this study, assuming a meaningful difference in the cortisol level between the groups of $40 \%$ (20.8 $\mu \mathrm{g} / \mathrm{dl})$, at least 19 patients were necessary per group when the alpha value with Bonferroni correction and power were set to $0.0125(0.05 / 4)$ and 0.9 , respectively. Considering a dropout rate of $10 \%, 21$ patients in each group (total 42 patients) were required.

\section{Statistical Analysis}

Serum cortisol, ACTH, and glucose levels were com- pared using repeated-measures ANOVA followed by the Student t-test or Mann-Whitney U-test with Bonferroni correction based on the normality test results. Other continuous variables were also compared using the Student t-test or Mann-Whitney U-test. Categorical variables such as the number of patients with intraoperative hypotension or early postoperative AI and the incidence of postoperative complications and postoperative 3-month pituitary hormone deficiency were analyzed using the chi-square or Fisher's exact tests. All data are expressed as means (standard deviation) for normally distributed continuous variables, medians (IQR) for nonnormally distributed variables, and numbers (percentage) for categorical variables. Statistical analysis was performed using IBM SPSS software (version 25, IBM Corp.).

\section{Results}

From September 2017 to October 2018, 47 patients without AI scheduled for ETSS at 8 AM for removal of an NFPA were enrolled. Among these patients, 5 patients were excluded due to preoperative use of steroids, refusal of informed consent, and a history of previous craniotomy (Fig. 1). The remaining 42 patients were randomized. Two patients were additionally excluded from the data analysis due to withdrawal of informed consent and change in the operating schedule. The final analysis included 40 patients. The general characteristics, tumor-related variables, preoperative pituitary hormonal status, and surgical variables did not significantly differ between the two groups (Table 1).

Intraoperative serum cortisol levels showed a significant time-group interaction between the two groups in repeated-measures ANOVA ( $p<0.001)$. The serum cortisol level was significantly higher in the HC group than in the $\mathrm{C}$ group after anesthesia induction (median $69.0 \mu \mathrm{g}$ / dl [IQR 62.2-89.6 $\mu \mathrm{g} / \mathrm{dl}]$ vs $12.7 \mu \mathrm{g} / \mathrm{dl}[8.4-18.2 \mu \mathrm{g} / \mathrm{dl}]$; median difference $57.5 \mu \mathrm{g} / \mathrm{dl}$ [95\% CI 33.0-172.9 $\mu \mathrm{g} / \mathrm{dl}]$ ), after dura incision (median $53.2 \mu \mathrm{g} / \mathrm{dl}$ [IQR 44.9-63.8 $\mu \mathrm{g} /$ dl] vs $6.4 \mu \mathrm{g} / \mathrm{dl}$ [IQR $4.8-9.2 \mu \mathrm{g} / \mathrm{dl}$ ]; median difference $46.6 \mu \mathrm{g} / \mathrm{dl}[$ [95\% CI 13.3-89.2 $\mu \mathrm{g} / \mathrm{dl}]$ ), after tumor removal (median $49.5 \mu \mathrm{g} / \mathrm{dl}$ [IQR $43.6-62.4 \mu \mathrm{g} / \mathrm{dl}]$ vs $9.2 \mu \mathrm{g} / \mathrm{dl}$ [IQR 5.75-16.7 $\mu \mathrm{g} / \mathrm{dl}]$; median difference $39.4 \mu \mathrm{g} / \mathrm{dl}$ [95\% CI $0.3-78.1 \mu \mathrm{g} / \mathrm{dl}]$ ), and at the end of surgery (median 46.9 $\mu \mathrm{g} / \mathrm{dl}$ [IQR 40.1-63.4 $\mu \mathrm{g} / \mathrm{dl}]$ vs $16.9 \mu \mathrm{g} / \mathrm{dl}$ [IQR 12.1-23.2 $\mu \mathrm{g} / \mathrm{dl}$ ]; median difference $32.2 \mu \mathrm{g} / \mathrm{dl}$ [ $95 \% \mathrm{CI}-42.0$ to $228.1 \mu \mathrm{g} / \mathrm{dl}]$; Fig. 2). There was no correlation between total doses of anesthetic and serum cortisol levels measured at the end of surgery within and between groups.

Serum ACTH levels were significantly lower in the HC group than in the $\mathrm{C}$ group after anesthesia induction (median $3.9 \mathrm{pmol} / \mathrm{L}$ [IQR $1.7-5.2 \mathrm{pmol} / \mathrm{L}$ ] vs $6.9 \mathrm{pmol} / \mathrm{L}$ [IQR 3.9-11.9 pmol/L], p = 0.007; Fig. 2). Blood glucose concentrations were significantly higher in the HC group than in the $\mathrm{C}$ group after tumor removal (median $6.97 \mathrm{mmol} / \mathrm{L}$ [IQR 6.48-7.22 mmol/L] vs $6.22 \mathrm{mmol} / \mathrm{L}$ [IQR 5.60-6.68 $\mathrm{mmol} / \mathrm{L}], \mathrm{p}=0.009$ ) and at the end of surgery (median $6.66 \mathrm{mmol} / \mathrm{L}$ [IQR $6.27-6.99 \mathrm{mmol} / \mathrm{L}]$ vs $5.97 \mathrm{mmol} / \mathrm{L}$ [IQR 5.48-6.65 mmol/L] mmol/L, p = 0.011; Fig. 2).

The incidences of intraoperative and postoperative hypotension, tachycardia, and bradycardia were not sig- 


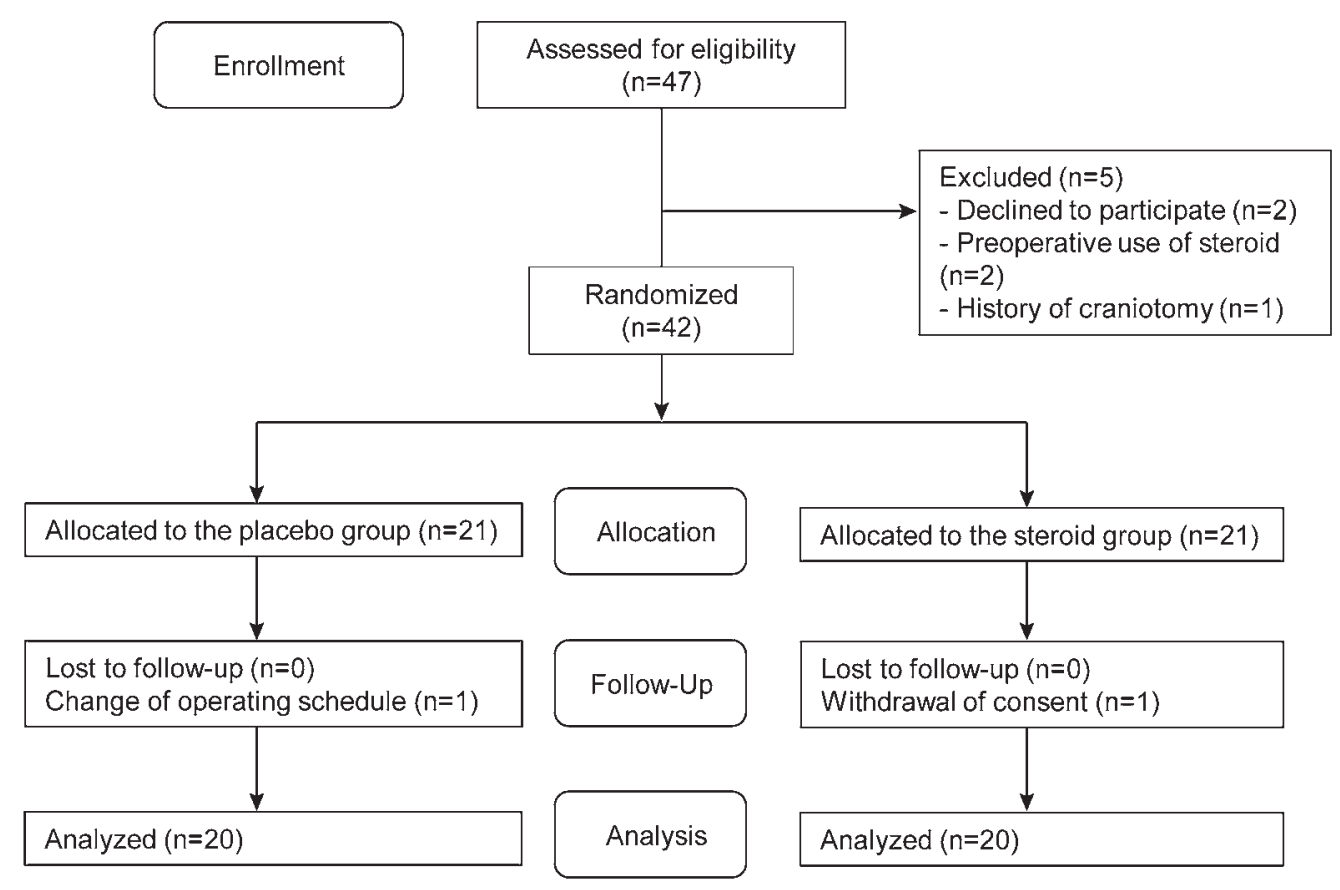

FIG. 1. CONSORT flowchart.

nificantly different between the two groups (Table 2). No patient was treated with intravenous hydrocortisone due to perioperative hemodynamic instability and showed intraoperative and immediate postoperative hyponatremia. PONV occurred in 2 patients in each group.

Early postoperative AI was observed in 3 and 5 patients in groups $\mathrm{HC}$ and $\mathrm{C}$, respectively (Table 3 ). No differences in serum cortisol levels in the morning on postoperative days $1-3$, or in the incidence of postoperative complications such as CNS infection, CSF leakage, hemorrhage, hydrocephalus, delayed hyponatremia, and diabetes insipidus were observed between the two groups. No difference in the pituitary function test at 3 months after surgery was observed.

\section{Discussion}

In the present study, higher cortisol levels at all intraoperative time points, lower ACTH levels after tumor removal, and higher glucose levels after tumor removal and at the end of surgery were observed in patients treated with preoperative hydrocortisone (group $\mathrm{HC}$ ) compared with patients treated with placebo (group C). A clinically significant sign of AI was not observed intraoperatively in either group. The incidences of early postoperative AI and postoperative complications, as well as 3-month postoperative pituitary function, were not significantly different between the two groups.

To date, measurement of intraoperative cortisol concentrations during ETSS for NFPA has been performed in only 1 study. In a recent small observational study conducted by Borg et al., ${ }^{3}$ serum cortisol concentrations were measured every 30 minutes after anesthesia induction in ACTH-sufficient patients undergoing ETSS in the morning with $(n=4)$ or without $(n=4)$ preoperative steroid administration. However, in the present study, serum cortisol levels were compared between the two groups at four specific time points (after anesthesia induction, after dura incision, after tumor removal, and at the end of surgery) to evaluate neuroendocrine stress response of anesthesia and surgery. In the results of the study by Borg et al., serum cortisol concentrations were approximately 3.5-7.5 $\mu \mathrm{g} / \mathrm{dl} 30 \mathrm{~min}-$ utes after anesthesia induction and approximately 16.3$23.6 \mu \mathrm{g} / \mathrm{dl}$ after intrasellar manipulation in ACTH-sufficient patients without preoperative steroid administration, whereas serum cortisol concentrations were approximately $18.1-45.3 \mu \mathrm{g} / \mathrm{dl} 30$ minutes after anesthesia induction and approximately 19.9-39.9 $\mu \mathrm{g} / \mathrm{dl}$ after intrasellar manipulation in patients with steroid replacement. Similarly, this study showed that serum cortisol levels were significantly higher in patients with preoperative steroid administration during the entire surgical period. The nadir serum cortisol concentration was $2.2 \mu \mathrm{g} / \mathrm{dl}$ in group C after anesthesia induction. However, the serum cortisol concentration increased to $4.3,5.6$, and $9.5 \mu \mathrm{g} / \mathrm{dl}$ after dura incision, after tumor removal, and at the end of surgery, respectively.

The results from this study showed that serum ACTH levels after anesthesia induction were significantly lower in patients with steroid administration than in those without. In addition, serum cortisol levels and ACTH levels showed similar changes over time in patients without steroid administration (a decrease in serum levels of both hormones before tumor removal and thereafter an increase in serum levels of both hormones), but opposite changes in patients with steroid administration (a continuous slow decrease in serum cortisol level during the entire surgical period but continuous elevation in serum ACTH level). Considering the half-life of serum cortisol (approximately 
TABLE 1. Comparisons of general characteristics, tumor-related variables, preoperative pituitary hormonal status, and intraoperative data between the two groups

\begin{tabular}{|c|c|c|c|}
\hline Variable & Group HC $(n=20)$ & Group C $(n=20)$ & p Value \\
\hline Mean age $\pm S D$, yrs & $48 \pm 16$ & $50 \pm 14$ & 0.771 \\
\hline Females, $\mathrm{n}(\%)$ & $11(55)$ & $12(60)$ & 1.000 \\
\hline Median weight (IQR), kg & $68(60-75)$ & $66(57-75)$ & 0.626 \\
\hline Median height (IQR), $\mathrm{cm}$ & $168(159-171)$ & $162(157-167)$ & 0.598 \\
\hline Mean $\mathrm{BMI} \pm \mathrm{SD}, \mathrm{kg} / \mathrm{m}^{2}$ & $25.2 \pm 2.9$ & $25.3 \pm 4.6$ & 0.949 \\
\hline \multicolumn{4}{|l|}{ Comorbidity, n (\%) } \\
\hline Diabetes mellitus & $0(0)$ & $1(5)$ & 1.000 \\
\hline Hypertension & $2(10)$ & $4(20)$ & 0.661 \\
\hline Hepatic & $0(0)$ & $2(10)$ & 0.487 \\
\hline Renal & $0(0)$ & $2(10)$ & 0.487 \\
\hline Pulmonary & $1(5)$ & $1(5)$ & 1.000 \\
\hline \multicolumn{4}{|l|}{ Tumor size } \\
\hline Mean anteroposterior diameter $\pm \mathrm{SD}, \mathrm{mm}$ & $19.5 \pm 6.8$ & $24.3 \pm 8.1$ & 0.051 \\
\hline Mean height $\pm \mathrm{SD}, \mathrm{mm}$ & $29.1 \pm 9.3$ & $29.8 \pm 10.2$ & 0.819 \\
\hline Width \pm SD, mm & $27.9 \pm 7.7$ & $29.1 \pm 7.0$ & 0.607 \\
\hline Median volume (IQR), $\mathrm{cm}^{3}$ & $8.2(4.6-13.8)$ & $8.2(5.9-12.3)$ & 0.665 \\
\hline \multicolumn{4}{|l|}{ Preop hormone level } \\
\hline Median cortisol (IQR), $\mu \mathrm{g} / \mathrm{dl}$ & $14.3(10.7-15.8)$ & $15.5(11.8-18.6)$ & 0.323 \\
\hline Mean ACTH \pm SD, pmol/L & $10.1 \pm 54.4$ & $10.6 \pm 44.0$ & 0.764 \\
\hline Median glucose (IQR), mmol/L & $5.75(5.33-6.16)$ & $5.36(5.16-6.18)$ & 0.255 \\
\hline \multicolumn{4}{|l|}{ Preop hormone deficiency, $\mathrm{n}(\%)$} \\
\hline None & $0(0)$ & $1(5)$ & 1.000 \\
\hline ACTH & $0(0)$ & $0(0)$ & NA \\
\hline TSH & $0(0)$ & $1(5)$ & 1.000 \\
\hline GN & $15(75)$ & $15(75)$ & 1.000 \\
\hline $\mathrm{GH}$ & $18(90)$ & $17(85)$ & 1.000 \\
\hline Mean anesthesia time $\pm S D$, mins & $140 \pm 25$ & $141 \pm 26$ & 0.905 \\
\hline Median op duration (IQR), mins & $73(64-95)$ & $75(65-91)$ & 0.479 \\
\hline Median total propofol dose (IQR), mg & $1400(1100-1800)$ & $1300(1100-1625)$ & 0.559 \\
\hline Median total remifentanil dose (IQR), $\mu \mathrm{g}$ & $1000(850-1425)$ & $1100(925-1450)$ & 0.486 \\
\hline Cavernous sinus invasion, $\mathrm{n}(\%)$ & $6(30)$ & $9(45)$ & 0.514 \\
\hline Optic chiasm compression, $\mathrm{n}(\%)$ & $18(90)$ & $20(100)$ & 0.487 \\
\hline Degree of resection, $\mathrm{n}(\%)$ & & & 0.235 \\
\hline Gross-total & $18(90)$ & $14(70)$ & \\
\hline Subtotal & $2(10)$ & $6(30)$ & \\
\hline
\end{tabular}

$\mathrm{NA}=$ not applicable.

Hydrocortisone $100 \mathrm{mg}$ (HC group) or placebo (C group) was administered to patients undergoing endoscopic transsphenoidal pituitary adenoma surgery in the morning on the day of surgery.

120 minutes) and ACTH (approximately 30 minutes) after steroid administration, ${ }^{2}$ these findings suggest that the negative feedback mechanism of the HPA axis is activated in patients with an intact HPA axis when they receive exogenous steroid administration.

In this study, intraoperative hypotension was observed in $45 \%$ and $40 \%$ of patients in the C and HC groups, respectively. However, because all episodes of intraoperative hypotension with a short duration occurred during anesthesia induction and were treated with a small bolus of vasopressor or fluid administration, the association of intraoperative hypotension with AI was not considered. In addition, the incidence of early postoperative AI did not differ between patients with and without preoperative steroid administration. Similarly, in previous retrospective and prospective observational studies, perioperative steroid administration was shown to have no effect on the incidence of early postoperative AI in patients without preoperative AI undergoing ETSS. ${ }^{10,12,13,27}$

Since a case series in the 1950s showing intraoperative hemodynamic collapse after acute steroid withdrawal in chronic steroid users, steroid replacement has been used 


\section{A. Cortisol $(\mu \mathrm{g} / \mathrm{dL})$}

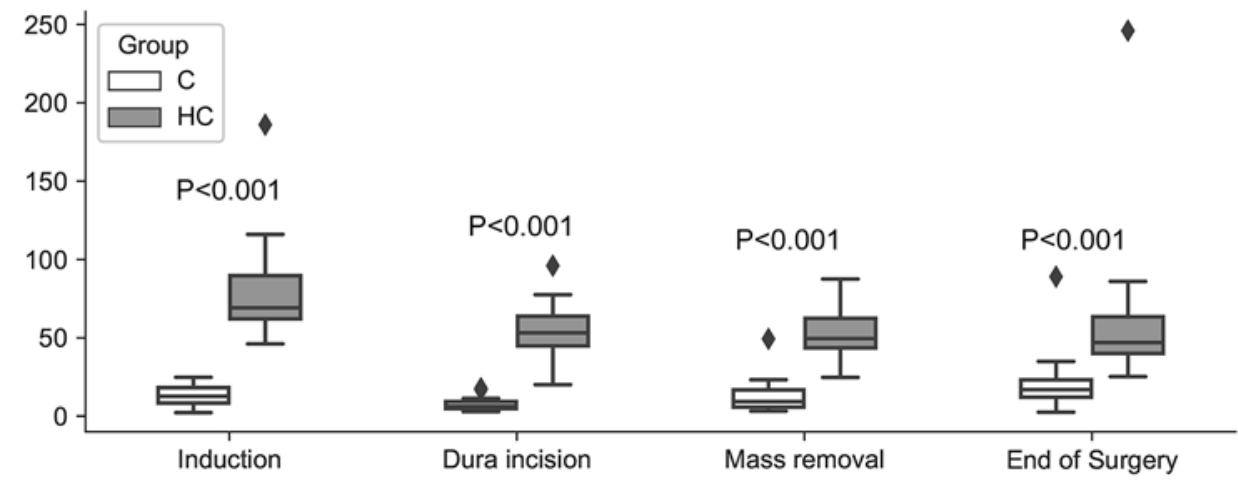

B. ACTH (pmol/L)

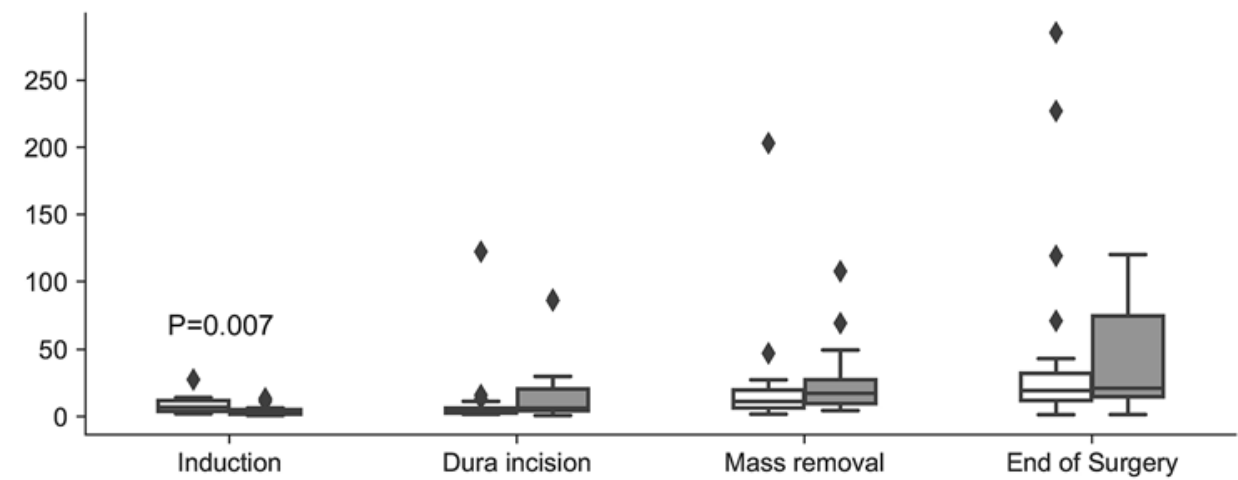

C. Glucose (mmol/L)

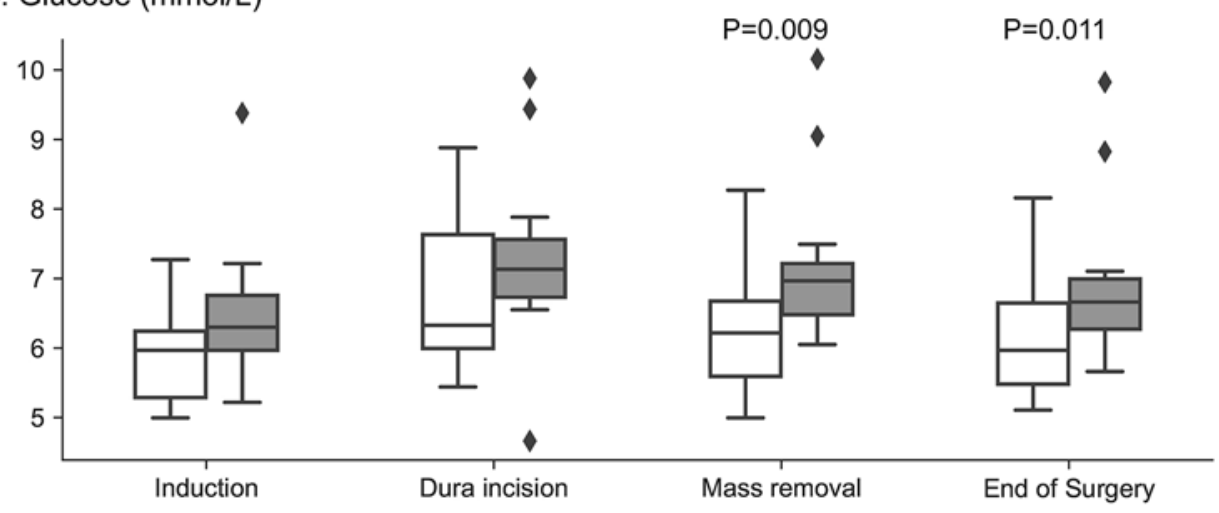

Time points

FIG. 2. Box plot of comparisons of intraoperative cortisol, ACTH, and glucose concentrations between the two groups. Line, box, and whiskers represent median, IQR, and 1.5 times the IQR. Diamonds represent outliers that are outside of 1.5 times the IQR. The $p$ values are derived from the Mann-Whitney U-test. Hydrocortisone $100 \mathrm{mg}$ (group HC) or placebo (group C) was administered to patients undergoing endoscopic transsphenoidal pituitary adenoma surgery in the morning on the day of surgery.

for several decades. ${ }^{9}, 18$ However, in a recent review, perioperative stress-dose steroid replacement was suggested to be unnecessary, even in patients with confirmed suppression of the HPA axis preoperatively due to chronic steroid use. ${ }^{19}$ In that study, no clinically significant sign of AI was observed in patients without preoperative steroid replacement during surgery. Similarly, in previous observational studies on patients with preoperative preserved function of the HPA axis undergoing transsphenoidal pituitary sur- gery, intraoperative cardiovascular collapse did not occur in patients without preoperative steroid administration. ${ }^{7,27}$

In this study, the incidence of early postoperative $\mathrm{AI}$ (serum morning cortisol concentration $<5 \mu \mathrm{g} / \mathrm{dl}$ on postoperative days 1-3) was as high as $15 \%$ and $25 \%$ in groups $\mathrm{HC}$ and $\mathrm{C}$, respectively. In contrast with our results, a recent study reported that the incidence of early postoperative AI was $4.8 \%$ in patients undergoing ETSS for sellar lesions. ${ }^{14}$ Also, a previous meta-analysis showed that the incidence 
TABLE 2. Comparisons of perioperative hemodynamic events between the two groups

\begin{tabular}{|c|c|c|c|c|}
\hline Hemodynamic Event & $\begin{array}{l}\text { Group HC } \\
(n=20)\end{array}$ & $\begin{array}{l}\text { Group C } \\
(n=20)\end{array}$ & $\begin{array}{l}\text { Risk Difference } \\
\quad(95 \% \mathrm{Cl})\end{array}$ & $\mathrm{p}$ Value \\
\hline \multicolumn{5}{|l|}{ Intraop } \\
\hline Hypotension, SBP $<80$ mm Hg & $8(40 \%)$ & $9(45 \%)$ & $-5 \%(-36$ to 26$)$ & 1.000 \\
\hline Median hypotension duration (IQR), mins & $2.0(1.0-3.8)$ & $1.0(1.0-3.5)$ & & 0.506 \\
\hline Tachycardia, HR >120 bpm & $2(10 \%)$ & $2(10 \%)$ & $0 \%(-19$ to 19$)$ & 1.000 \\
\hline Median tachycardia duration (IQR), mins & $2.0(1.0-2.0)$ & $1.0(1.0-1.0)$ & & 0.317 \\
\hline Bradycardia, $\mathrm{HR}<40$ bpm & $3(15 \%)$ & $0(0 \%)$ & $15 \%(-1$ to 31$)$ & 0.231 \\
\hline Median bradycardia duration (IQR), mins & $2.0(1.0-2.0)$ & None & NA & NA \\
\hline \multicolumn{5}{|l|}{ Postop at ICU } \\
\hline Hypotension, SBP $<80$ mm Hg & $1(5 \%)$ & $0(0 \%)$ & $5 \%(-5$ to 15$)$ & 1.000 \\
\hline Hypotension duration, mins & 4 & None & & NA \\
\hline Tachycardia, HR >120 bpm & $0(0 \%)$ & $0(0 \%)$ & NA & NA \\
\hline Bradycardia, $\mathrm{HR}<40$ bpm & $0(0 \%)$ & $0(0 \%)$ & NA & NA \\
\hline Nausea or vomiting & $2(10 \%)$ & $2(10 \%)$ & $0 \%(-18.6$ to 18.6$)$ & 1.000 \\
\hline
\end{tabular}

of early postoperative AI ranged from $1 \%$ to $13 \%$, with an overall incidence of 5.5\%. ${ }^{31}$ This difference in the incidence of early postoperative AI between our study and previous reports is due to a different sample size. A small sample size in this study is not sufficient to evaluate the incidence of early postoperative AI. In this study, the overall incidence of postoperative 3-month ACTH deficiency was $20 \%$. Similarly, a previous study demonstrated that new postoperative 3-month ACTH deficiency occurred in $20 \%$ of patients without preoperative AI after ETSS for NFPA. ${ }^{15}$

In the present study, significant differences in serum glucose concentrations were observed between the two groups after tumor removal and at the end of surgery.

TABLE 3. Comparisons of postoperative cortisol levels, complications, and hormonal status between the two groups

\begin{tabular}{|c|c|c|c|c|}
\hline Variable & Group HC $(n=20)$ & Group C $(n=20)$ & $\begin{array}{l}\text { Risk Difference } \\
\quad(95 \% \mathrm{Cl})\end{array}$ & $p$ Value \\
\hline Early postop Al, n (\%) & $3(15)$ & $5(25)$ & $10 \%(-15$ to 35$)$ & 0.695 \\
\hline \multicolumn{5}{|l|}{ Morning cortisol levels, $\mu \mathrm{g} / \mathrm{dl}$} \\
\hline Median postop day 1 (IQR) & $16.1(11.6-19.9)$ & $22.5(10.5-34.7)$ & & 0.346 \\
\hline Median postop day 2 (IQR) & $10.7(4.7-15.5)$ & $11.9(8.7-18.8)$ & & 0.305 \\
\hline Mean postop day $3 \pm$ SD & $10.6 \pm 6.5$ & $15.6 \pm 7.9$ & & 0.071 \\
\hline \multicolumn{5}{|l|}{ Postop complication, n (\%) } \\
\hline CNS infection & $0(0)$ & $0(0)$ & NA & NA \\
\hline CSF leakage & $0(0)$ & $0(0)$ & NA & NA \\
\hline Hemorrhage & $0(0)$ & $0(0)$ & NA & NA \\
\hline Hydrocephalus & $0(0)$ & $0(0)$ & NA & NA \\
\hline Delayed hyponatremia & $3(15)$ & $4(20)$ & $5 \%(-18$ to 28$)$ & 1.000 \\
\hline Transient diabetes insipidus & $3(15)$ & $9(45)$ & $30 \%(3-57)$ & 0.084 \\
\hline Permanent diabetes insipidus & $0(0)$ & $1(5)$ & $5 \%(-5$ to 15$)$ & 1.000 \\
\hline \multicolumn{5}{|l|}{$\begin{array}{l}\text { Hormone deficiency at } 3 \text { mos } \\
\text { postop, } n(\%)\end{array}$} \\
\hline None & $3(15)$ & $2(10)$ & $-5 \%(-27$ to 17$)$ & 1.000 \\
\hline ACTH & $2(10)$ & $6(30)$ & $20 \%(-4$ to 44$)$ & 0.235 \\
\hline TSH & $0(0)$ & $3(15)$ & $15 \%(-1$ to 31$)$ & 0.231 \\
\hline GN & $12(60)$ & $11(55)$ & $-5 \%(-36$ to 26$)$ & 1.000 \\
\hline $\mathrm{GH}$ & $15(75)$ & $16(80)$ & $5 \%(-21$ to 31$)$ & 1.000 \\
\hline Panhypopituitarism & $0(0)$ & $1(5)$ & $5 \%(-5$ to 15$)$ & 1.000 \\
\hline
\end{tabular}


However, because the incidence of hyperglycemia above 7 $\mathrm{mmol} / \mathrm{L}$ did not differ between groups, whether this mild increase in the serum glucose concentration is clinically significant is difficult to evaluate. In a previous meta-analysis, a significant association between hyperglycemia and postoperative complications was not found in neurosurgical patients. ${ }^{1}$

Postoperative sodium disturbances such as diabetes insipidus and hyponatremia, known to be associated with pituitary manipulation and relocation of the pituitary gland, are common complications after pituitary surgery. ${ }^{16}$ In a previous meta-analysis, the incidence of diabetes insipidus after pituitary surgery was not different between the steroid and the nonsteroid groups. ${ }^{31}$ The present study results also failed to show a difference in the incidence of postoperative diabetes insipidus and delayed hyponatremia between the two groups.

This study had several limitations. First, anesthetic techniques may have affected the neuroendocrine stress response. Specifically, total intravenous anesthesia using propofol and remifentanil decreases the intraoperative cortisol level compared with inhalation anesthesia., ${ }^{4,17}$ However, total intravenous anesthesia is widely implemented in neurosurgery due to its advantages of smooth recovery, reduced intracranial pressure, and prevention of PONV. ${ }^{5,8}$ Second, the sample size of this study was too small to evaluate the incidences of perioperative AI and postoperative 3-month ACTH deficiency. A large-scale randomized study or meta-analysis is needed to verify the effects of preoperative steroid administration on these clinically meaningful events. Third, the results were obtained from patients whose surgery started at 8 AM. Due to circadian changes in serum cortisol levels, generalizing the results from the present study to patients operated on in the afternoon is difficult. Fourth, in this study, the blood samples were stored in an ice chest and sent to the hospital laboratory as a batch after the end of surgery, and then the results were reported in the late afternoon on the day of surgery. Therefore, although all of the neurosurgeons, anesthesiologists, and intensivists were blinded to the patient group, it was possible that intensivists could infer the patient group from the results on intraoperative serum cortisol levels during the postoperative period. Finally, this study included only patients with NFPAs. Therefore, extrapolating the results to patients with functional pituitary adenomas or nonpituitary sellar/parasellar tumors may be limited.

\section{Conclusions}

Preoperative steroid administration in patients without AI undergoing ETSS for NFPAs resulted in significantly increased intraoperative cortisol levels. However, no patient showed intraoperative hemodynamic instability due to AI. The incidence of early postoperative AI, postoperative complications, and postoperative 3-month ACTH deficiency did not differ between patients with and those without preoperative steroid administration. The results from the present study indicate that preoperative steroid administration may be unnecessary in patients without AI undergoing ETSS for NFPAs. However, a further large- scale study is needed to determine whether preoperative steroid administration has a significant impact on clinically meaningful events such as perioperative $\mathrm{AI}$ and postoperative 3-month ACTH deficiency in these patients.

\section{Acknowledgments}

This study was supported by grant no. 04-2017-0880 from the Seoul National University Hospital Research Fund. All costs for laboratory tests and medications for this study were supported by the grant.

\section{References}

1. Atkins JH, Smith DS: A review of perioperative glucose control in the neurosurgical population. J Diabetes Sci Technol 3:1352-1364, 2009

2. Berson SA, Yalow RS: Radioimmunoassay of ACTH in plasma. J Clin Invest 47:2725-2751, 1968

3. Borg H, Siesjö P, Kahlon B, Fjalldal S, Erfurth EM: Perioperative serum cortisol levels in ACTH sufficient and ACTH deficient patients during transsphenoidal surgery of pituitary adenoma. Endocrine 62:83-89, 2018

4. Citerio G, Pesenti A, Latini R, Masson S, Barlera S, Gaspari F, et al: A multicentre, randomised, open-label, controlled trial evaluating equivalence of inhalational and intravenous anaesthesia during elective craniotomy. Eur J Anaesthesiol 29:371-379, 2012

5. Cote DJ, Burke WT, Castlen JP, King CH, Zaidi HA, Smith TR, et al: Safety of remifentanil in transsphenoidal surgery: a single-center analysis of 540 patients. J Clin Neurosci 38:96-99, 2017

6. de Lange DW, Kars M: Perioperative glucocorticosteroid supplementation is not supported by evidence. Eur J Intern Med 19:461-467, 2008

7. De Tommasi C, Goguen J, Cusimano MD: Transphenoidal surgery without steroid replacement in patients with morning serum cortisol below $9 \mu \mathrm{g} / \mathrm{dl}(250 \mathrm{Nmol} / \mathrm{l})$. Acta Neurochir (Wien) 154:1903-1915, 2012

8. Degli Uberti EC, Petraglia F, Bondanelli M, Guo AL, Valentini A, Salvadori S, et al: Involvement of mu-opioid receptors in the modulation of pituitary-adrenal axis in normal and stressed rats. J Endocrinol Invest 18:1-7, 1995

9. Fraser CG, Preuss FS, Bigford WD: Adrenal atrophy and irreversible shock associated with cortisone therapy. J Am Med Assoc 149:1542-1543, 1952

10. García-Luna PP, Leal-Cerro A, Rocha JL, Trujillo F, GarciaPesquera F, Astorga R: Evaluation of the pituitary-adrenal axis before, during and after pituitary adenomectomy. Is perioperative glucocorticoid therapy necessary? Acta Endocrinol (Copenh) 122:83-88, 1990

11. Giannoudis PV, Dinopoulos H, Chalidis B, Hall GM: Surgical stress response. Injury 37 (Suppl 5):S3-S9, 2006

12. Hout WM, Arafah BM, Salazar R, Selman W: Evaluation of the hypothalamic-pituitary-adrenal axis immediately after pituitary adenomectomy: is perioperative steroid therapy necessary? J Clin Endocrinol Metab 66:1208-1212, 1988

13. Inder WJ, Hunt PJ: Glucocorticoid replacement in pituitary surgery: guidelines for perioperative assessment and management. J Clin Endocrinol Metab 87:2745-2750, 2002

14. Jackanich A, Tavakol S, Strickland BA, Rutkowski M, Kamel D, Carmichael JD, et al: Clinical utility of routine postoperative morning cortisol monitoring in detecting new hypothalamic-pituitary-adrenal axis insufficiency following endoscopic transsphenoidal surgery for sellar lesions. J Neurosurg [epub ahead of print March 1, 2019. DOI: 10.3171/2018.11.JNS182521]

15. Kim JH, Lee JH, Lee JH, Hong AR, Kim YJ, Kim YH: Endoscopic transsphenoidal surgery outcomes in 331 nonfunc- 
tioning pituitary adenoma cases after a single surgeon learning curve. World Neurosurg 109:e409-e416, 2018

16. Kristof RA, Rother M, Neuloh G, Klingmüller D: Incidence, clinical manifestations, and course of water and electrolyte metabolism disturbances following transsphenoidal pituitary adenoma surgery: a prospective observational study. J Neurosurg 111:555-562, 2009

17. Ledowski T, Bein B, Hanss R, Paris A, Fudickar W, Scholz $\mathrm{J}$, et al: Neuroendocrine stress response and heart rate variability: a comparison of total intravenous versus balanced anesthesia. Anesth Analg 101:1700-1705, 2005

18. Lewis L, Robinson RF, Yee J, Hacker LA, Eisen G: Fatal adrenal cortical insufficiency precipitated by surgery during prolonged continuous cortisone treatment. Ann Intern Med 39:116-126, 1953

19. Liu MM, Reidy AB, Saatee S, Collard CD: Perioperative steroid management: approaches based on current evidence. Anesthesiology 127:166-172, 2017

20. Mauricio Del Rio J, Nicoara A, Swaminathan M: Neuroendocrine stress response: implications for cardiac surgery-associated acute kidney injury. Rom J Anaesth Intensive Care 24:57-63, 2017

21. Miller DB, O'Callaghan JP: Neuroendocrine aspects of the response to stress. Metabolism 51 (6 Suppl 1):5-10, 2002

22. Molitch ME: Diagnosis and treatment of pituitary adenomas: a review. JAMA 317:516-524, 2017

23. Okinaga H, Matsuno A, Okazaki R: High risk of osteopenia and bone derangement in postsurgical patients with craniopharyngiomas, pituitary adenomas and other parasellar lesions. Endocr J 52:751-756, 2005

24. Peacey SR, Guo CY, Robinson AM, Price A, Giles MA, Eastell R, et al: Glucocorticoid replacement therapy: are patients over treated and does it matter? Clin Endocrinol (Oxf) 46:255-261, 1997

25. Pecoraro NC, Heiferman DM, Martin B, Li D, Johans SJ, Patel CR, et al: Lower-dose perioperative steroid protocol during endoscopic endonasal pituitary adenoma resection. Surg Neurol Int 10:52, 2019

26. Prete A, Corsello SM, Salvatori R: Current best practice in the management of patients after pituitary surgery. Ther Adv Endocrinol Metab 8:33-48, 2017

27. Regan J, Watson J: Selective use of peri-operative steroids in pituitary tumor surgery: escape from dogma. Front Endocrinol (Lausanne) 4:30, 2013
28. Russell G, Lightman S: The human stress response. Nat Rev Endocrinol 15:525-534, 2019

29. Smith SM, Vale WW: The role of the hypothalamic-pituitaryadrenal axis in neuroendocrine responses to stress. Dialogues Clin Neurosci 8:383-395, 2006

30. Sterl K, Thompson B, Goss CW, Dacey RG, Rich KM, Zipfel GJ, et al: Withholding perioperative steroids in patients undergoing transsphenoidal resection for pituitary disease: randomized prospective clinical trial to assess safety. Neurosurgery 85:E226-E232, 2019

31. Tohti M, Li J, Zhou Y, Hu Y, Yu Z, Ma C: Is peri-operative steroid replacement therapy necessary for the pituitary adenomas treated with surgery? A systematic review and meta analysis. PLoS One 10:e0119621, 2015

32. Zueger T, Kirchner P, Herren C, Fischli S, Zwahlen M, Christ $\mathrm{E}$, et al: Glucocorticoid replacement and mortality in patients with nonfunctioning pituitary adenoma. J Clin Endocrinol Metab 97:E1938-E1942, 2012

\section{Disclosures}

The authors report no conflict of interest concerning the materials or methods used in this study or the findings specified in this paper.

\section{Author Contributions}

Conception and design: all authors. Acquisition of data: Lee, Yoon. Analysis and interpretation of data: Lee, JH Kim, YH Kim. Drafting the article: Lee. Critically revising the article: JH Kim, YH Kim. Reviewed submitted version of manuscript: Park, JH $\mathrm{Kim}, \mathrm{YH}$ Kim. Approved the final version of the manuscript on behalf of all authors: Park. Statistical analysis: Lee. Study supervision: Park.

\section{Correspondence}

Hee-Pyoung Park: Seoul National University College of Medicine, Seoul National University Hospital, Seoul, Korea. hppark@ snu.ac.kr. 